\title{
PERAN BIDAN PRAKTIK SWASTA DALAM PEMBERIAN ASI EKSKLUSIF DI WILAYAH KERJA PUSKESMAS ABIANSEMAL IV KABUPATEN BADUNG
}

\author{
Ni Wayan Dian Titrawati*, Ni Komang Ekawati, Desak Nyoman Widyanthini \\ Program Studi Kesehatan Masyarakat Fakultas Kedokteran Universitas Udayana \\ *E-mail: diantitra22@gmail.com
}

\begin{abstract}
ABSTRAK
Cakupan ASI Eksklusif pada tahun 2016 di Wilayah Kerja Puskesmas Abiansemal IV masih rendah yaitu 77\%. Peran bidan praktik swasta sangat penting untuk keberhasilan dalam pemberian ASI Eksklusif. Tujuan dari penelitian ini adalah untuk mengetahui peran bidan praktek swasta dalam pemberian ASI Eksklusif di Wilayah Kerja Puskesmas Abiansemal IV Kecamatan Abiansemal Kabupaten Badung. Penelitian ini merupakan penelitian kualitatif dengan teknik pengambilan sampel purposive sampling. Metode pengambilan data dilakukan dengan wawancara mendalam pada 8 orang informan yaitu ibu-ibu yang mempunyai bayi usia 0-24 bulan dan 4 orang informan kunci yaitu bidan praktik swasta. Selain itu dilakukan juga observasi di tempat bidan praktik swasta. Hasil penelitian ini menunjukkan bidan praktik swasta memberikan informasi ASI Eksklusif pada saat antenatal care yaitu ketika kehamilan ibu memasuki trimester ketiga dan pemberian informasi ASI Eksklusif juga dilakukan ketika bayi lahir serta pada saat evaluasi perilaku pemberian ASI Eksklusif. Namun terdapat satu bidan praktik swasta yang menyediakan susu formula. Persepsi ibu terhadap peran bidan cukup baik karena menurut ibu, bidan praktik swasta memberikan pelayanan yang ramah, namun tidak semua mendapatkan perawatan payudara di bidan praktik swasta. Ibu yang mendapatkan informasi yang lengkap dari bidan memiliki pengetahuan yang baik terkait ASI Eksklusif. Meskipun pengetahuan ibu baik namun tidak memberikan ASI Eksklusif karena mengalami hambatan. Kesimpulan dari penelitian ini adalah bidan berperan cukup baik dalam pemberian informasi ASI Eksklusif yaitu pada saat kehamilan ibu memasuki trimester ketiga dan pada saat ibu sudah melahirkan bayi, pengetahuan ibu pada manfaat lebih baik dibandingkan dengan pengertian ASI Eksklusif, persepsi ibu terhadap peran bidan praktik swasta cukup baik, hanya satu orang ibu yang telah memberikan ASI Eksklusif. Saran yang dapat diberikan adalah kerjasama antara pihak puskesmas dan bidan praktik swasta lebih ditingkatkan terkait promosi ASI Eksklusif, Puskesmas Abiansemal IV dapat memberikan leaflet atau brosur terkait pemberian ASI Eksklusif kepada bidan praktik swasta serta penelitian ini dapat dijadikan sumber referensi untuk penelitian selanjutnya terkait alasan-alasan ibu tidak memberikan ASI Eksklusif.
\end{abstract}

Kata kunci: Peran Bidan Praktik Swasta, Pengetahuan Ibu, Perilaku Ibu, Persepsi Ibu Terhadap Peran Bidan Praktik Swasta

\begin{abstract}
Coverage of exclusive breastfeeding in 2016 in the working area of Abiansemal IV Puskesmas was still low at $77 \%$. The role of private practice midwives is crucial for success in exclusive breastfeeding. The purpose of this study was to determine the role of private practice midwives in exclusive breastfeeding in the working area of Abiansemal IV Health Center, Abiansemal District, Badung Regency. This research is a qualitative research with purposive sampling technique. The data collection method was carried out by in-depth interviews with 8 informants namely mothers who have babies aged 0-24 months and 4 key informants namely private practice midwives. In addition, observations were also made at the private practice midwife's place. The results of this study indicate that private practice midwives provide information on exclusive breastfeeding during antenatal care, namely when the mother's pregnancy enters the third trimester and exclusive breastfeeding information is also performed when the baby is born and at the time of evaluating the behavior of exclusive breastfeeding. But there is one private practice midwife who provides formula milk. The mother's perception of the role of the midwife is quite good because according to the mother, the private practice midwife provides friendly service, but not all get breast care at the private practice midwife. Mothers who get complete information from midwives have good knowledge related to exclusive breastfeeding. Even though the mother's knowledge is good, she does not provide exclusive breastfeeding due to obstacles. The conclusion of this study is that midwives play a fairly good role in providing exclusive breastfeeding information, namely when the mother's pregnancy enters the third trimester and when the mother
\end{abstract}


has given birth to a baby, the mother's knowledge of benefits is better than the understanding of exclusive breastfeeding, the mother's perception of the role of private practice midwife well, only one mother has given exclusive breastfeeding. Suggestions that can be given are cooperation between the puskesmas and private practice midwives to be improved in relation to the promotion of exclusive breastfeeding, Abiansemal IV Puskesmas can provide leaflets or brochures related to exclusive breastfeeding to private practice midwives and this research can be used as a reference source for further research related to reasons mother does not give exclusive breastfeeding.

Keywords: Role of Private Practice Midwives, Mother's Knowledge, Mother's Behavior, Mother's Perception of the Role of Private Practice Midwives

\section{PENDAHULUAN}

Berdasarkan Peraturan Pemerintah Nomor 33 Tahun 2013 ASI Eksklusif merupakan ASI yang diberikan kepada bayi sejak bayi dilahirkan selama 6 bulan pertama kehidupan tanpa menambahkan atau mengganti dengan makanan dan minuman lainnya kecuali obat, vitamin, dan mineral (Kemenkes RI, 2015).

Data Ditjen Kesehatan Masyarakat, Kemenkes RI tahun 2016 mengungkapkan bahwa cakupan pemberian ASI Eksklusif telah mencapai target sebesar $55,7 \%$ dari target 39\%. Berdasarkan laporan 33 provinsi di Indonesia, sebanyak 29 provinsi telah mencapai target pemberian ASI Eksklusif. Cakupan pemberian ASI Eksklusif di Provinsi Bali pada tahun 2015 adalah sebesar 72,8\% (Kemenkes RI, 2015).

Menurut data kabupaten/kota Provinsi Bali hanya terdapat dua kabupaten yang mencapai target program provinsi adalah Kabupaten Jembrana sebesar 84,7\% dan Kabupaten Gianyar sebesar 80,02\% dan terdapat tiga kabupaten dengan capaian pemberian ASI Eksklusif terendah yaitu Kabupaten Buleleng (61,95\%), Kabupaten Karangasem (69,68\%) dan Kabupaten Badung hanya 70,29\% (Dinkes Prov Bali, 2015). Salah satu kecamatan di Kabupaten Badung yang cakupan ASI Eksklusif rendah adalah Kecamatan Abiansemal di wilayah kerja Puskesmas Abiansemal IV yaitu hanya $77 \%$.

Peran bidan dalam mensosialisasikan pemberian ASI Eksklusif dapat dimulai sejak ibu hamil. Ketika ibu hamil memeriksakan kehamilannya, ibu hamil akan mendapatkan informasi mengenai keuntungan memberikan ASI dan bagaimana cara sukses menyusui saat kelahiran bayinya kelak (Atik, 2016). Berdasarkan analisis situasi awal di lapangan, bidan sangat berperan dalam keberhasilan ibu memberikan ASI Eksklusif. Bidan memberikan edukasi tentang ASI Eksklusif terhadap ibu yang melahirkan di tempat bidan praktik swasta.

Berdasarkan pengamatan awal dilapangan, seorang bidan di puskesmas abiansemal IV menyatakan bahwa ibu yang sedang hamil dan mempunyai bayi di wilayah Puskesmas Abiansemal IV banyak yang memeriksakan kehamilannya dan melahirkan bayinya dibantu oleh seorang bidan. Bukan hanya bidan yang bekerja di puskesmas tetapi juga bidan praktik swasta. Berdasarkan data dari puskesmas, diwilayah kerja puskesmas Abiansemal IV terdapat enam bidan praktek swasta. Empat bidan praktik swasta melakukan praktik di Desa Bongkasa, satu bidan praktik di Desa Taman dan satu bidan di Desa Selat yang merupakan wilayah kerja puskesmas IV. Meskipun bidan praktik swasta melakukan 
praktik paling banyak di wilayah Desa Bongkasa, namun cakupan ASI Eksklusif masih rendah. Hal inilah yang mendorong penulis untuk melakukan penelitian tentang "Peran Bidan Praktik Swasta dalam Pemberian ASI Eksklusif di Wilayah Kerja Puskesmas Abiansemal IV Kabupaten Badung Tahun 2017".

Tujuan dari penelitian ini adalah untuk mengetahui peran bidan praktik swasta dalam pemberian ASI Eksklusif di Wilayah Kerja Puskesmas Abiansemal IV Kecamatan Abiansemal Kabupaten Badung.

\section{METODE PENELITIAN}

Penelitian ini merupakan penelitian deskriptif dengan pendekatan kualitatif. Penelitian ini dilaksanakan di Desa Bongkasa yang merupakan wilayah kerja Puskesmas Abiansemal IV. Teknik sampling yang digunakan adalah purposive sampling. Pengumpulan data dilakukan dengan teknik wawancara mendalam dan observasi. Wawancara mendalam dilakukan kepada delapan orang ibu yang mempunyai bayi usia 0-24 bulan sebagai informan dan empat orang bidan praktik swasta sebagai key informan. Observasi dilakukan di tempat praktik bidan praktik swasta.

Penelitian ini telah mendapatkan persetujuan etik dari Komisi Etik Fakultas Kedokteran Universitas Udayana/RSUP Sanglah.

\section{HASIL DAN DISKUSI}

Berdasarkan penelitian yang telah dilakukan diperoleh bahwa peranan bidan praktik swasta berupa memberikan informasi dengan mempromosikan serta mengedukasi ibu yang berkunjung ke tempat praktik terkait ASI Eksklusif.
Menurut bidan praktik swasta yang telah diwawancarai, pemberian ASI Eksklusif sangat penting untuk pertumbuhan dan perkembangan bayi. Bidan praktik swasta memberikan informasi ASI Eksklusif melalui tahapannya yaitu ketika bayi lahir dan ada juga bidan yang mengatakan ketika kehamilan ibu memasuki trimester ketiga. Berikut kutipan wawancaranya adalah: "Pemberian informasi ASI Eksklusif dilakukan ketika ibu sudah melahirkan"

"Iya dikasih tau pas itu dah kan tergantung dari kehamilan, nanti kan dilihat umur kehamilan berapa nanti kita kasih KIE dia sesuai umur kehamilan dan sesuai buku pinknya, biasanya ngasih info ASI Eksklusif pas masuk TW 3".

Hal ini selaras dengan informasi yang didapat dari ibu-ibu yaitu bidan praktik swasta memberikan informasi terkait ASI Eksklusif ketika bayi sudah lahir. Informasi yang diberikan berupa pengertian ASI Eksklusif, manfaat untuk bayi serta manfaat selain untuk bayi. Adapun kutipan wawancaranya adalah:

"Iya dikasih tahu pas bayinya udah lahir gek"

Pemberian informasi terkait ASI Eksklusif disesuaikan dengan buku kesehatan ibu dan anak yang merupakan panduan yang digunakan oleh bidan praktik swasta. Buku kesehatan ibu dan anak berisikan catatan kesehatan ibu selama hamil, bersalin dan masa nifas atau pasca persalinan serta catatan anak dari bayi baru lahir sampai anak usia enam tahun. Selain itu buku kesehatan ibu dan anak juga berisikan tentang cara memelihara dan merawat kesehatan ibu dan anak (Kemenkes RI, 2015). Pada penelitian yang telah dilakukan semua ibu yang mendapatkan buku kesehatan ibu dan anak tidak pernah dijelaskan oleh bidan praktik 
swasta mengenai isi dari buku kesehatan ibu dan anak tersebut. Ibu-ibu yang berkunjung ke tempat bidan praktik swasta hanya disuruh membaca buku kesehatan ibu dan anak oleh bidan.

Bidan praktik swasta juga memberikan pelayanan antenatal care terkait kondisi kandungan. Adapun kutipan wawancara mendalamnya adalah :

"ANC pemeriksaan kandungan biasanya mulai dari timbang, pemeriksaan DJJ, pengukuran tinggi badan, pemeriksaan lingkar lengan, tinggi fundus uteri, pemberian tablet besi, imunisasi TT, informasi diberikan sesuai dengan buku kesehatan ibu dan anak"

Selain pemeriksaan kandungan, bidan praktik swasta juga memberikan pelayanan perawatan payudara dengan tujuan agar air susu ibu keluar pada saat bayi lahir sehingga bayi bisa diberikan susu sesegera mungkin atau bisa dilakukan inisiasi menyusui dini (IMD). Berikut kutipan wawancaranya :

"Iya kita menyarankan pas ANC dah, gini caranya merawat payudara supaya nanti pas melahirkan langsung mau keluar, ditunjukkan caranya bagaimana" (K3).

Ibu-ibu yang mendapatkan pelayanan payudara oleh bidan praktik swasta mengatakan perawatan payudara dilakukan ketika ibu memeriksakan kehamilan. Adapun kutipan wawancaranya adalah :

"Eeee pas periksa hamil ada dikasih tahu sama bidannya gimana caranya membersihkan payudara supaya ASInya mau keluar katanya"

Selain mendapatkan informasi mengenai kandungan, sebagian ibu-ibu juga mendapatkan penjelesan mengenai perawatan payudara. Bidan praktik swasta menyruh ibu untuk membersihkan puting payudara dengan rajin sehingga pada saat melahirkan air susu ibu langsung keluar. Perawatan payudara merupakan suatu cara untuk merawat payudara yang dilakukan pada saat masa kehamilan ibu atau pasa saat setelah ibu melahirkan. Pelaksanaan perawatan payudara bertujuan untuk memperlancar produksi ASI, untuk kebersihan payudara dan membantu mengeluarkan puting yang retraksi atau putting yang masuk ke dalam.

Salah satu tujuan dari pelayanan antenatal care adalah untuk mempersiapkan ibu agar masa nifas berjalan normal dan mempersiapkan ibu agar bisa memberikan ASI Eksklusif pada bayinya. Salah satu penanganan kesehatan pada ibu hamil yang harus dilakukan oleh bidan adalah menjelaskan cara merawat payudara (Depkes RI, 2007).

Selain pemberian informasi serta pelaksanaan antenatal care, bidan praktik swasta juga melakukan evaluasi kepada ibu yang mempunyai bayi terkait pemberian ASI Eksklusif. Evaluasi dilakukan dengan menyuruh ibu untuk mengunjungi tempat bidan praktik swasta. Adapun kutipan wawancaranya adalah :

"Evaluasi dilakukan ketika ibu mengunjungi tempat praktik"

Selain itu, hasil wawancara mendalam kepada informan menyatakan bahwa bidan menanyakan kepada ibu terkait pemberian ASI Eksklusif. Adapun kutipan wawancara mendalamnya sebagai berikut :

"Iya kan disuruh kontrol lagi sama bidannya... pas itu ditanyain udah ngasik ASI apa belum terus dipencet juga payudaranya sama bidannya benar mau keluar ASInya atau tidak" (I2) 
Evaluasi perilaku ibu atau pasien dilakukan pada pasca persalinan dengan cara menyuruh ibu atau pasien untuk kontrol setiap sebulan sekali setelah melahirkan bayi. Kontrol ini biasa disebut dengan kunjungan nifas dan kunjungan neonatal. Masa nifas adalah masa yang dimulai dari plasenta lahir sampai berakhir ketika organ-organ kandungan sudah kembali seperti keadaan sebelum melahirkan. Tujuan diberikannya asuhan pada masa nifas adalah menjaga kesehatan ibu dan bayinya, melaksnaakan skrining yang komprehensif, menganalisa data untuk mendeteksi masalah pada ibu da bayi, mengobati atau merujuk ibu atau bayi apabila ada komplikasi, memberikan pendidikan kesehatan tentang perawatan kesehatan diri, nutrisi, keluara berencana, menyusui, imunisasi pada bayi serta perawatan bayi sehat (Kemenkes RI, 2014).

Terdapat satu bidan praktik swasta yang menyediakan susu formula di tempat praktik. Bidan tersebut menyediakan susu formula dengan tujuan untuk menyiapkan apabila ASI tidak langsung keluar ketika bayi lahir sehingga bayi terhindar dari kekurangan cairan. Adapun pernyataan dari bidan tersebut adalah :

"Kalau sebenarnya itu kan tidak diperbolehkan ya, tapi ya namanya pasien kan kadang ada ASInya tidak mau keluar sammpai 2-3 hari setelah melahirkan itu saya memang menyarankan untuk memberikan susu formula...."

Hal tersebut juga didukung oleh pernyataan oleh salah satu informan yang melahirkan di tempat bidan praktik swasta tersebut. Adapun hasil wawancaranya sebagai berikut: “...karna ASInya gak mau langsung keluar pas itu langsung dikasih susu sama bidannya... biar gak bayinya kuning katanya kan sekarang kebanyakan bayi kuning... bidannya emang nyediaiin susu formula gek.. bidannya yang jual.."

Hasil observasi juga menunjukkan bahwa di tempat bidan praktik swasta terdapat satu contoh susu formula yang disediakan oleh bidan tersebut.

Berdasarkan penelitian yang dilakukan oleh Pratiwi dkk (2015) dengan judul penelitian hubungan peran bidan dengan perilaku pemberian ASI Eksklusif pada ibu yang memiliki bayi usia 0-6 bulan di Kelurahan Bawen Kecamatan Bawen Kabupaten Semarang menyatakan bahwa salah satu faktor yang menyebabkan kurangnya peranan bidan dalam promosi ASI Eksklusif karena bidan masih mempromosikan susu formula. Penyediaan susu formula di tempat praktik bidan dengan pandangan untuk meningkatkan gizi bayi menyebabkan ibu untuk memberikan susu formula. Hal ini dibuktikan dengan hasil penelitian tersebut menyatakan bahwa sebanyak 52\% responden mengatakan bidan mempromosikan susu formula untuk bayi kepada ibu.

Berdasarkan hasil penelitian, perilaku ibu yang mendapatkan informasi secara lengkap dari bidan praktik swasta memiliki pengetahuan yang baik dan memberikan ASI Eksklusif untuk bayinya karena tidak mengalami hambatan. Selain itu, pemberian ASI Eksklusif dikarenakan faktor dari ibu yang memang air susunya langsung keluar ketika bayi lahir. 


\section{SIMPULAN}

Dalam penelitan ini bidan praktik swasta memberikan informasi atau edukasi terkait ASI Eksklusif pada saat antenatal care yaitu ketika kehamilan ibu memasuki trimester tiga dan informasi diberikan saat ibu bayi sudah lahir serta pada saat mengevaluasi perilaku ibu dalam pemberian ASI Eksklusif. Pada saat antenatal care juga dilakukan perawatan payudara. Peran bidan praktik swasta juga didukung oleh hasil observasi yang telah dilakukan bahwa bidan telah menyediakan ruangan untuk bersalin, ruangan nifas, penyediaan buku kesehatan ibu dan anak, penyediaan gambar atau poster terkait ASI Eksklusif. Namun masih ada bidan praktik swasta yang menyediakan susu formula di tempat praktik. Pengetahuan ibu lebih baik pada manfaat ASI Eksklusif dibandingkan dengan pengetahuan ibu terkait pengertian ASI Eksklusif. Persepsi ibu terhadap peranan bidan praktik swasta terkait pemberian ASI Eksklusif baik. Perilaku ibu dalam memberikan ASI Eksklusif sangat dipengaruhi oleh pengetahuan ibu. Ibu yang berperilaku memberikan ASI Eksklusif karena memiliki pengetahuan yang baik dan tidak mengalami hambatan dalam pemberian ASI Eksklusif. Namun ada juga ibu yang tidak memberikan ASI Eksklusif karena mengalami hambatan meskipun pengetahuannya baik.

\section{SARAN}

Pihak UPT. Puskesmas Abiansemal IV dalam melakukan promosi ASI Eksklusif bisa bekerjasama dengan Bidan Praktik Swasta dengan menjalin kemitraan. Selain itu pihak puskesmas juga bisa menitipkan atau membagikan brosur atau leaflet pada bidan praktik swasta terkait ASI Eksklusif. Untuk peneliti selanjutnya yang ingin melakukan penelitian sejenis diharapkan penelitian ini dapat dijadikan sumber informasi untuk meneliti alasan-alasan ibu dalam pemberian ASI Eksklusif.

\section{DAFTAR PUSTAKA}

Atik Nur Sri, Hadi Mestuti \& Kristiani Ika S. (2016). Hubungan Karakteristik Bidan dan Motivasi dengan Pencapaian Cakupan ASI Eksklusif. Available at: http://akbidmr.ac.id/wpcontent/uploads/2016/04/1-10hubungan-karakteristik-bidan-danmotivasi-dengan-pencapaiancakupan-asi-eksklusif.pdf. (akses: 27 Januari 2017).

Dinas Kesehatan Provinsi Bali. (2015). Profil Kesehatan Provinsi Bali tahun 2014. Denpasar, Bali.

Kementerian Kesehatan RI. 2014. Situasi dan Analisis ASI Eksklusif. Jakarta: Pusat Data dan Informasi Kementerian Kesehatan RI.Kementerian Kesehatan RI. 2015. Rencana Strategis Kementerian Kesehatan Tahun 2015-2019. Jakarta: Kementerian Kesehatan Republik Indonesia

Kementerian Kesehatan RI. 2016. Pedoman Pekan ASI Sedunia (PAS) Tahun 2016. Jakarta: Kemenkes RI Direktorat Gizi Masyarakat

Lewins, A. et al. (2010). What is Qualitative Data Analysis (QDA)?. Available at: http://onlineqda.hud.ac.uk/intro_qd 
Arc. Com. Health Juni 2019

ISSN: 2527-3620

a/what_is_qda.php (akses 27 Januari 2016).

Pratiwi, dkk. (2015). Hubungan Peran Bidan dengan Perilaku Pemberian ASI Eksklusif pada Ibu yang Memiliki Bayi Usia 0-6 bulan di Kelurahan Bawen Kecamatan Bawen Kabupaten Semarang. Available at: http://perpusnwu.web.id/karyailmi ah/documents/4640.pdf. (akses: 16 Agustus 2017). 